\title{
Brain metastasis from hepatocellular carcinoma: the role of surgery as a prognostic factor
}

\author{
Moon-Soo Han ${ }^{1}$, Kyung-Sub Moon ${ }^{1 *}$, Kyung-Hwa Lee ${ }^{2}$, Sung-Bum Cho ${ }^{3}$, Sa-Hoe Lim', Woo-Youl Jang ${ }^{1}$, \\ Tae-Young Jung ${ }^{1}$, In-Young Kim ${ }^{1}$ and Shin Jung ${ }^{1}$
}

\begin{abstract}
Background: The incidence of brain metastasis from hepatocellular carcinoma (HCC) is expected to increase as a result of prolonged survival due to the recent advances in HCC treatment. However, there is no definite treatment strategy for brain metastasis from HCC mainly due to its rarity and dismal prognosis. To provide helpful recommendations in treatment of brain metastasis from HCC, the authors aimed to identify prognostic factors that influence survival rates with a review of the recently published data.
\end{abstract}

Methods: Thirty-three cases of brain metastasis, whose incidence was $0.65 \%$, were selected from a total of 5015 HCC patients and reviewed retrospectively in terms of clinical and radiological features.

Results: Median overall survival time after diagnosis of brain metastasis was 10.4 weeks (95\% confidence interval [Cl], 5.1-15.7 weeks) with 1-, 6- and 12-month survival rates, of 79\%, 24\% and 6\%, respectively. Median survival of the patients treated with surgical resection or surgical resection followed by whole-brain radiation therapy (WBRT) (25.3 weeks; range, 15.8-34.8 weeks) was longer than that of the patients treated with gamma knife surgery (GKS), WBRT, or GKS followed by WBRT (10.4 weeks; range, 7.5-13.3 weeks) as well as that of patients treated with only steroids (1 week; range, 0.0-3.3 weeks) ( $<$ 0.001). Child-Pugh's classification A group had a longer median survival time than Child-Pugh's classification B or C group (14.4 weeks vs 8.4 weeks, $p=0.038$ ). RPA class I \& II group had also a longer median survival time than RPA class III group did (13.4 weeks vs 2.4 weeks, $p=0.001$ ). Surgical resection (hazard ratio [HR] 0.23, 95\% Cl 0.08-0.66, $p=0.006$ ) and good liver function at the time of brain metastasis (HR 0.25, 95\% Cl 0.09-0.69, $p=0.007$ ) were found to be the powerful prognostic factors for favorable survival in the multivariate analysis. In addition, presence of intratumoral hemorrhage was a statistically significant prognostic factor for survival.

Conclusion: Although HCC patients with brain metastasis showed a very dismal prognosis, surgical intervention was shown to lead to relative prolongation of the survival time, especially in those with preserved hepatic function.

Keywords: Brain metastasis, Hepatocellular carcinoma, Prognosis, Surgical resection, Survival

\section{Background}

Hepatocellular carcinoma (HCC) is one of the most common malignant tumors worldwide [1]. Its incidence is particularly high in Southeast Asia and sub-Saharan Africa where hepatitis $B$ and $C$ infections are the most prevalent [1]; however, a significant increase in the incidence of HCC has been recently observed in Australia and other Western countries [1]. Brain metastasis from HCC is so rare that the incidence was reported to be only about $0.6 \%[2]$. The

\footnotetext{
*Correspondence: moonks@chonnam.ac.kr

'Department of Neurosurgery, Chonnam National University Research Institute of Medical Sciences, Chonnam National University Hwasun Hospital \& Medical School, Gwangju, South Korea

Full list of author information is available at the end of the article
}

recent therapeutic advances including surgical techniques, transarterial chemoembolization (TACE), local ablation, and chemotherapeutic agents, have all contributed to improved survival rates [3]. The incidence of brain metastasis, therefore, is expected to increase as a result of prolonged survival of HCC patients [4]. The prognosis for patients having brain metastasis from HCC is very poor [5-7]. There have been no definite recommendations for the management of the brain metastasis from HCC, because of its rarity and poor prognosis.

In the present study, the authors aimed to elucidate the incidence of brain metastasis from HCC and to identify prognostic factors that influence survival rates. 
In addition, we reviewed the literature to identify prognostic factors for survival in patients with brain metastasis from HCC.

\section{Methods}

The study is in compliance with the Declaration of Helsinki (Sixth Revision, 2008). This study fulfills all the requirements for patient anonymity was approved by the institutional review board of Chonnam National University Medical School Research Institution (2013-67). Of a total 5015 HCC patients who were diagnosed and treated at our hospital between 2001 and 2012, 33 patients were retrospectively confirmed as having brain metastasis from HCC, using cranial computed tomography (CT) and/or magnetic resonance imaging (MRI) and by reviewing the hospital charts.

To define the clinical characteristics of the patients with brain metastasis from HCC, clinical data at the time of diagnosis of brain metastasis, including age, sex, presenting symptoms, time interval from diagnosis of primary tumor to brain metastasis, Eastern cooperative oncology group (ECOG) performance status [8], Child-Pugh classification [9], recursive partitioning analysis (RPA) class [10], level of alpha fetoprotein (AFP), treatment modality, and survival time were collected. Additionally, we also evaluated the radiological findings such as the presence of extracranial metastasis and main portal vein thrombosis, number and type of HCC nodule, size of the largest HCC nodule, number of brain lesions, concomitant intratumoral hemorrhagic changes and location of the brain lesion.

ECOG performance status described six grades to determine the appropriate treatment and prognosis [8]: Grade 0: Fully active, able to carry on all pre-disease performance; Grade 1: Restricted in physically strenuous activity but ambulatory and able to carry out work of a light or sedentary nature; Grade 2: Ambulatory and capable of all self-care but unable to carry out any work activities, Up and about more than 50\% of waking hours; Grade 3: Capable of only limited self-care, confined to bed or chair more than 50\% of waking hours; Grade 4: Completely disabled. Cannot carry on any self-care. Totally confined to bed or chair; Grade 5: Dead.

Child-Pugh classification [9] includes the factors of hepatic encephalopathy, ascites, total bilirubin level, albumin level, and prolonged prothrombin time. Child-Pugh A category is defined as a score of $5-6$, Child-Pugh B category is defined as a score of 7-9, and Child-Pugh $C$ category is defined as a score of $10-15$. Overall survival was calculated from the date of diagnosis of brain metastasis until death, or until the date of the last follow-up visit for patients who were still alive.

RPA classification describes three classes to predict survival of patients with brain metastases [10]: Class I: patients with a Karnofsky performance status (KPS) $>70$, age $<65$ years with controlled primary disease and no evidence of extracranial metastases; Class III: patients with a KPS $<70$, and Class II: all remaining patients who do not fit into Classes 1 or III. Stratified Mantel-Cox log-rank test for each factor was applied to compare the KaplanMeier curves for survival. The factors that might predict overall survival in HCC patients with brain metastasis were analyzed using a multivariate logistic regression model. All statistical analyses were performed using SPSS version 20.0 software program for Windows (SPSS, Chicago, IL, USA). The level of significance was set at $\mathrm{P}<0.05$.

\section{Results}

\section{Clinical presentation}

The incidence of brain metastasis from HCC was $0.65 \%$ in our patient group (33/5015). Clinical characteristics of the enrolled patients are summarized in Table 1 . The median age at diagnosis of brain metastasis was 62 years (range, 23-80 years) and there was a male predominance (91\%). The most common presenting symptoms were headache, followed by motor weakness and mental status changes. The majority of the lesions were symptomatic (97\%), possibly due to the high incidence of intratumoral hemorrhage (52\%). The median time interval between diagnosis of $\mathrm{HCC}$ and diagnosis of brain metastasis was 18.3 months (range, 0.5-75 months). In RPA classification at the time of diagnosis of brain metastasis, the majority of the patients were grouped into class II (27 patients, $82 \%$ ) or III (4 patients, $12 \%)$. According to Child-Pugh classification for the severity of liver function, 20 patients $(61 \%)$ were classified into grade A, 13 patients (39\%) into grade B or C. Elevated AFP levels were found in only 10 patients (30\%). Viral hepatitis infection was detected in most of the patients $(85 \%)$ on serological study with a high prevalence of hepatitis B virus infection (76\%). In the aspect of HCC characteristics, only 8 patients (24\%) showed smaller number of nodule lesser than $4(<4)$. The maximum diameter of the HCC nodule was greater than $5 \mathrm{~cm}$ in 15 patients (45\%). Ill-defined types of HCC were found in 13 patients (39\%) and thrombosis of the main portal vein was present in 15 patients (45\%). Chemotherapy using a target agent (Sorafenib ${ }^{\circ}$ ) was applied in 10 patients (30\%).

Twenty-four patients (73\%) had lung metastasis at the time of detection of brain metastasis. Seventeen patients $(52 \%)$ had a single brain lesion.

\section{Treatment}

Accordingly, treatment methods were decided based on many factors, including general condition of the patient, the number and location of brain lesions, physician's and patients' personal preference. Treatment modalities for brain metastasis are summarized in Table 1. Ten patients underwent surgical resection and six of them subsequently received WBRT. Thirteen patients were 
Table 1 Clinical characteristics of 33 patients with brain metastases from HCC

\begin{tabular}{ll}
\hline Characteristic & No. of patients (\%) \\
\hline & HCC characteristics
\end{tabular}

Age in years at diagnosis of

brain metastasis; median (range)

62 (23-80yrs)

Sex

$\begin{array}{ll}\text { Male } & 30(91 \%) \\ \text { Female } & 3(9 \%)\end{array}$

Time in months from diagnosis of HCC

to brain metastases; median (range)

$18.3(0.5-75 \mathrm{mos})$

ECOG performance status

$$
\begin{aligned}
& \leq 2 \\
& \geq 3 \\
& \text { RPA class I } \\
& \text { II } \\
& \text { III } \\
& \text { Child-Pugh classification }
\end{aligned}
$$$$
\text { A }
$$

B

C

AFP (ng/ml)

$$
\leq 400
$$$$
>400
$$

unknown

Etiology

Hepatitis B

Hepatitis C

Alcoholic

Idiopathic

Number of tumor nodules

$$
1
$$$$
2-3
$$$$
\geq 4
$$

Largest tumor size $(\mathrm{cm})$

$<2$

$2-5$

6-10

$>10$

$21(64 \%)$

$12(36 \%)$

$2(6 \%)$

$27(82 \%)$

$4(12 \%)$

$20(61 \%)$

$11(33 \%)$

$2(6 \%)$

$18(55 \%)$

$10(30 \%)$

$5(15 \%)$

$25(76 \%)$

3 (9\%)

$4(12 \%)$

1 (3\%)

$3(9 \%)$

$5(15 \%)$

$25(76 \%)$

$4(12 \%)$

$14(43 \%)$

$12(36 \%)$

$3(9 \%)$

Tumor type

Well-defined

$20(61 \%)$

III-defined

$13(39 \%)$

Main portal vein thrombosis

Absent

$18(55 \%)$

Present

$15(45 \%)$

Previous treatment

Hepatic resection
Table 1 Clinical characteristics of 33 patients with brain metastases from HCC (Continued)

\begin{tabular}{ll}
\hline TACE & $27(82 \%)$ \\
RFA & $4(12 \%)$ \\
Chemotherapy (Sorafenib) & $10(30 \%)$ \\
Radiotherapy & $10(30 \%)$ \\
Site of extracranial metastases & \\
Lung & $24(73 \%)$ \\
Bone & $6(18 \%)$ \\
Lymph node & $8(24 \%)$ \\
Adrenal gland & $2(6 \%)$ \\
Skin & $1(3 \%)$ \\
None & $6(18 \%)$
\end{tabular}

Brain metastasis characteristics

Symptoms/signs

Headache

$18(55 \%)$

Motor disturbance

$12(36 \%)$

Mental status changes

$8(24 \%)$

Visual disturbance

$5(15 \%)$

Dizziness

$4(12 \%)$

Non-neurologic symptom

$1(3 \%)$

Number of lesions

Single

$17(52 \%)$

Multiple

$16(48 \%)$

Intratumoral hemorrhage

Yes

$17(52 \%)$

No

$16(48 \%)$

Location of brain metastases

\begin{tabular}{ll} 
Frontal & $5(15 \%)$ \\
Parietal & $6(18 \%)$ \\
Occipital & $2(6 \%)$ \\
Temporal & $1(3 \%)$ \\
Cerebellar & $1(3 \%)$ \\
Cavernous sinus & $1(3 \%)$ \\
Basal ganglia & $1(3 \%)$ \\
Multiple locations & $16(48 \%)$ \\
Treatment modalities & \\
Resection alone & $4(12 \%)$ \\
Resection + WBRT & $6(18 \%)$ \\
GKS alone & $11(33 \%)$ \\
GKS + WBRT & $2(6 \%)$ \\
WBRT alone & $4(12 \%)$ \\
Palliative (Steroid alone) & $6(18 \%)$ \\
\hline
\end{tabular}


treated with GKS, and four patients were treated with WBRT alone. Two patients who were previously treated with GKS showed tumor recurrence, and hence additional WBRT was performed in these patients. Six patients received conservative medical (palliative) treatment, mainly with steroids to reduce the increased intracranial pressure. All operation cases underwent gross total resection. Mean maximal and marginal doses of GKS were 36.4 Gy (range, 24-50 Gy) and 18 Gy (range, 14-25 Gy) prescribed to the $50 \%$ iso-dose line. The usual fractionation schedule for WBRT was 30 Gy in 10 fractions (Mean dose, $28.8 \mathrm{~Gy}$; range, 25-30 Gy).

\section{Overall survival and prognostic factors}

Patients with brain metastasis from $\mathrm{HCC}$ had poor outcomes. The median overall survival time after diagnosis of brain metastasis was 10.4 weeks (Figure 1. 95\% confidence interval [CI]: 5.1-15.7 weeks). The 1-, 6- and 12-month survival rates were $79 \%, 24 \%$ and $6 \%$, respectively. At the end of the follow up, 31 patients had died and two patients were alive (one in radiation treatment group and one resection group). The cause of death was identified in 29 patients (not defined in two cases; one in radiation treatment group and one in resection group). Seventeen patients died as a result of progressive diseases or systemic complications (hepatic failure, acute respiratory failure, and so on), and 12 patients died as a consequence of metastatic brain diseases. With palliative treatment using steroid, 5 patient died due to brain lesions $(5 / 6,83 \%)$. In the radiation treatment group, causes of death were neurologic-origin in 6 patients $(6 / 15,40 \%)$. Only one patients $(1 / 8,13 \%)$ died from

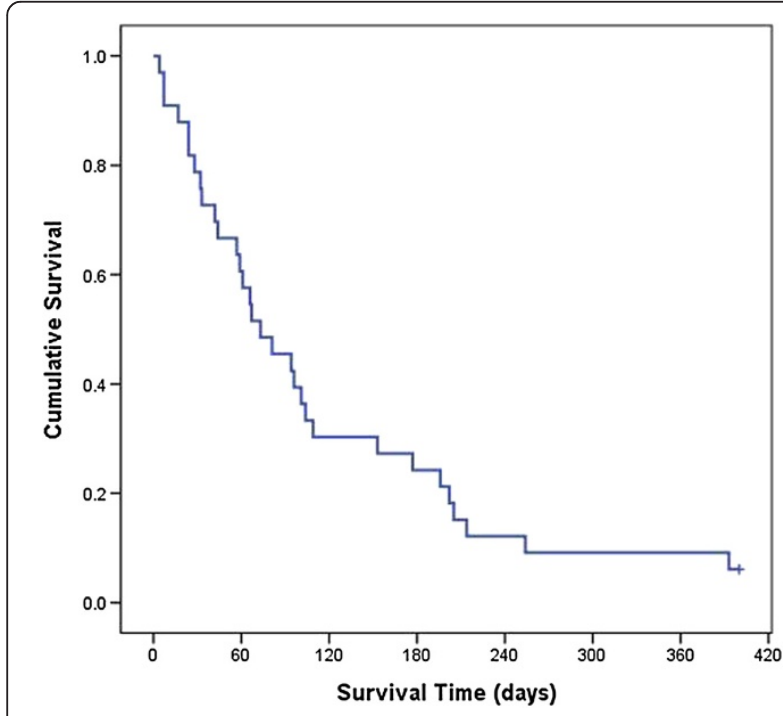

Figure 1 Overall survival in $\mathbf{3 3}$ patients after the diagnosis of brain metastasis from HCC. Note that the median survival was 10.4 weeks and 1-, 6- and 12-month survival rates were 79\%, 24\% and $6 \%$, respectively. neurologic cause (rebleeding on another small lesion) in the surgical resection group.

The results of analyses of the variables that could be correlated with survival time are shown in Table 2. On univariate analysis, RPA classification, Child-Pugh's classification, intratumoral hemorrhage, and treatment modality showed statistical significance (Figure 2). The patients with RPA class I or II showed a longer survival time than the patients with RPA class III did, with a statistical significance in univariate analysis ( 13.4 weeks $v s 2.4$ weeks, $\mathrm{p}=0.001$ ). In multivariate analysis, however, this difference was not statistically significant ( $\mathrm{p}=0.063)$.

Child-Pugh's classification A group had a longer median survival time than Child-Pugh's classification $\mathrm{B}$ or $\mathrm{C}$ group (14.4 weeks $v s 8.4$ weeks, $\mathrm{p}=0.038)$. The statistical significance remained meaningful in multivariate analysis (HR 0.25, 95\% CI 0.09-0.69, p=0.007). Patients without intratumoral hemorrhage had a longer median survival time than patients with intratumoral hemorrhage (13.7 weeks vs 8.1 weeks, $\mathrm{p}=0.044$ ). Furthermore, this difference reached statistical significance in multivariate analysis (HR 0.19, 95\% CI 0.07-0.55, p=0.002). With respect to the treatment modality for brain metastasis, surgical treatment was shown to lead to a longer survival time in univariate analysis $(\mathrm{p}<0.001)$; Median survival was 25.3 weeks (range, 15.8-34.8 weeks) for patients treated with surgical resection/surgical resection followed by WBRT, 10.4 weeks (range, 7.5-13.3 weeks) for patients treated with GKS followed by WBRT/GKS/WBRT, and only 1 week (range, 0.0-3.3 weeks) for patients treated with only steroids. In multivariate analysis, surgical resection was significantly associated with longer survival compared to non-resection treatment (HR 0.23, 95\% CI 0.08-0.66, $\mathrm{p}=0.006)$. Interestingly, the patients with a shorter interval ( $\leq 12$ months) from diagnosis of primary tumor to brain metastasis showed a longer survival time than the patients with a longer interval (>12 months) from diagnosis of primary tumor to brain metastasis, without statistical significance in multivariate analysis (15.6 weeks $v s 8.7$ weeks, $\mathrm{p}=0.089$ ). The younger age group ( $<60$ years) survived longer than the older age group, but the difference was not statistically significant in multivariate analysis (14.8 weeks vs 8.7 weeks, $\mathrm{p}=0.062$ ).

As shown in Figure 3, the univariate analysis demonstrated that HCC characteristics including the number of nodule, size of the largest nodule, type and presence of portal vein thrombosis were not correlated with the survival rate of the patients. In multivarate analysis, the patients without portal vein thrombosis survived longer than the patients with thrombosis did, with marginal statistical significance (10.4 weeks vs 8.7 weeks, $\mathrm{p}=0.065)$. The group with well-defined HCC type or HCC nodule less than 4 showed a longer survival than the group with ill-defined type or nodule over than 4. However, these 
Table 2 Univariate and multivariate analyses for survival predictors in patients with brain metastasis from HCC

\begin{tabular}{llllll}
\hline Variables & No & $\begin{array}{l}\text { Median } \\
\text { (wks) }\end{array}$ & $\begin{array}{l}\text { Univariate } \\
p \text {-value }\end{array}$ & Multivariate & \\
\cline { 5 - 7 } & & & $95 \% \mathrm{Cl}$ & $p$-value
\end{tabular}

AGE

$\begin{array}{llllll}<60 \text { years } & 17 & 14.8 & 0.096 & N D & 0.062 \\ \geq 60 \text { years } & 16 & 8.7 & & & \end{array}$

Sex

$\begin{array}{lccccc}\text { M } & 30 & 10.4 & 0.178 & \text { ND } & 0.144 \\ \text { F } & 3 & 8.4 & & & \\ \text { Symptoms }^{\#} & & & & & 0.552 \\ \text { Minor } & 17 & 11.6 & 0.412 & \text { ND } & \end{array}$

Interval of diagnosis from primary tumor to brain metastasis

$\begin{array}{llllll}\leq 12 \text { months } & 11 & 15.6 & 0.239 & \text { ND } & 0.089 \\ >12 \text { months } & 22 & 8.7 & & & \end{array}$

ECOG PS

$\begin{array}{lll}\leq 2 & 21 & 13.4 \\ >2 & 12 & 4.7\end{array}$

RPA class

| \& ||

III

$29 \quad 13.4$

0.001

$N D$

0.575

Child-Pugh's classification

A

$B / C$

$20 \quad 14.4$

0.038

0.25

$0.09-0.69 \quad 0.007$

Number of HCC nodules

$1-3$

$18 \quad 9.6$

0.389

1

$\geq 4$

$10 \quad 8.7$

Largest size of HCC

$\begin{array}{lll}\leq 5 \mathrm{~cm} & 18 & 14.4 \\ >5 \mathrm{~cm} & 15 & 6.0\end{array}$

HCC type

$\begin{array}{lll}\text { Well-defined } \quad 20 & 12.9\end{array}$

III-defined $\quad 13 \quad 8.7$

Main portal vein thrombosis

$\begin{array}{lll}\text { No } & 18 & 10 . \\ \text { Yes } & 15 & 8.7\end{array}$

Chemotherapy for HCC (Sorafenib)

No $23 \quad 96$

$\begin{array}{lll}\text { Yes } & 10 & 10.4\end{array}$

AFP

$\leq 400$

$>400$

$18 \quad 9.6$

$10 \quad 8.7$

Lung metastasis

No

$9 \quad 21.9$

0.197

$24 \quad 9.4$
Table 2 Univariate and multivariate analyses for survival predictors in patients with brain metastasis from HCC (Continued)

\begin{tabular}{|c|c|c|c|c|c|c|}
\hline \multicolumn{7}{|c|}{ Number of brain metastasis } \\
\hline Single & 17 & 13.7 & \multirow[t]{2}{*}{0.341} & \multicolumn{2}{|l|}{ ND } & 0.800 \\
\hline Multiple & 16 & 8.1 & & & & \\
\hline \multicolumn{7}{|c|}{ Hemorrhage of brain metastasis } \\
\hline No & 16 & 13.7 & \multirow[t]{2}{*}{0.044} & 0.19 & \multirow[t]{2}{*}{$0.07-0.55$} & 0.002 \\
\hline Yes & 17 & 8.1 & & 1 & & \\
\hline \multicolumn{7}{|c|}{ Treatment for brain metastasis } \\
\hline Resection \pm WBRT & 10 & 25.3 & \multirow[t]{3}{*}{$<0.001$} & 0.23 & \multirow[t]{3}{*}{$0.08-0.66$} & \multirow[t]{3}{*}{0.006} \\
\hline $\begin{array}{l}\text { GKS } \pm \text { WBRT / } \\
\text { WBRT alone }\end{array}$ & 17 & 10.4 & & $1^{*}$ & & \\
\hline Steroid alone & 6 & 1.0 & & & & \\
\hline
\end{tabular}

\# Minor; headache, dizziness, cranial nerve deficit, Major; mental status changes, motor weakness.

* Reference variable: non-resection treatment groups.

HCC; hepatocellular carcinoma, wks; weeks, AFP; alpha fetoprotein, WBRT; whole brain radiation therapy, GKS; gamma knife radiosurgery, ND; not determined.

differences did not reach a statistical significance in multivariate analysis (HCC type [10.4 weeks vs 8.7 weeks, $\mathrm{p}=$ 0.072], number of nodule [9.6 weeks vs 8.7 weeks, $\mathrm{p}=$ $0.088])$. Additionally, the usage of chemotherapeutic target agent (Sorafenib ${ }^{\circ}$ ) for HCC did not affect the patients' survival (10.4 weeks vs 9.6 weeks, $\mathrm{p}=0.583$ ).

\section{Discussion}

The incidence of brain metastasis in patients with HCC at our hospital was $0.65 \%$, and this finding was in accordance with in previous reports demonstrating an incidence ranging from 0.26 to $2.2 \%$ [5,11]. However, these numerical values probably underestimate the true incidence. In our hospital, brain imaging study is not a routine evaluation for HCC patients; and it is performed mainly in cases with neurologic symptoms. Therefore, asymptomatic patients with brain metastasis may have been missed. In this study, only one patient (3\%) was asymptomatic and found on a routine work-up for systemic progression.

The prognosis of brain metastasis from HCC is extremely poor. As summarized in Table 3, in the previously reported large studies, the median survival for patients with brain metastasis from HCC was from 4 to 12 weeks $[5-7,12,13]$. Similarly, the median survival was 10.4 weeks in our study. In a study by Han et al. [7], patients treated with WBRT and/or GKS had a longer median survival time than patients treated with surgical resection followed by WBRT (16 weeks $v s 8$ weeks). However, other studies have reported that surgical treatment may confer a survival benefit in patients with brain metastasis from $\mathrm{HCC}$ $[5,6,13]$. In our study, patients treated with surgical resection with/without postoperative WBRT had a longer median survival time than patients treated with GKS followed 

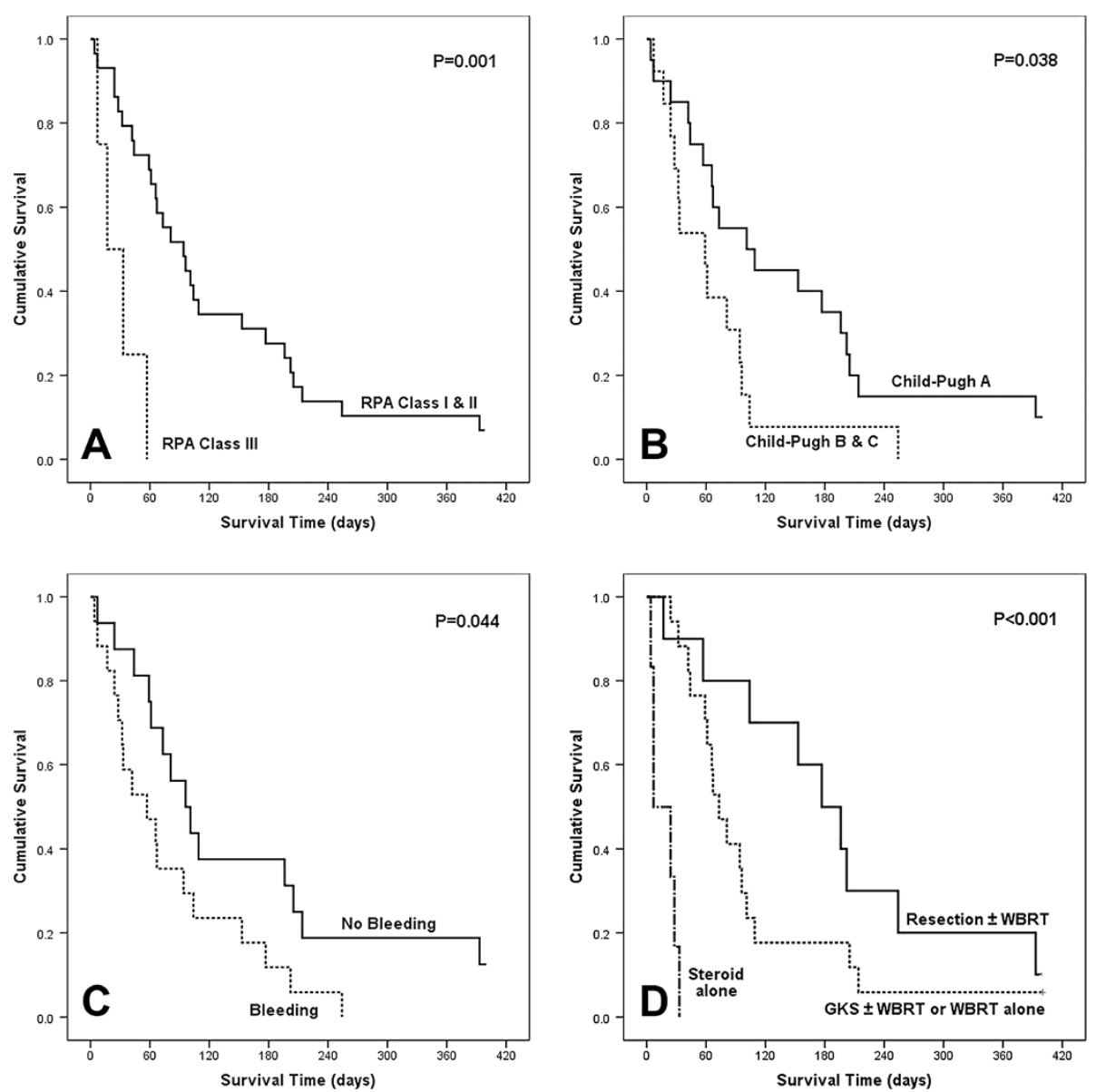

Figure 2 Kaplan-Meier analyses of overall survival for 33 patients according to different predictors. (overall comparison was estimated using a log-rank test). A: RPA class, B: Child-Pugh classification, C: Presence of intratumoral hemorrhage, D: Treatment modality for brain metastasis.

by WBRT/GKS/WBRT only or those treated with only steroids (25.3 weeks vs 10.4 weeks $v s 1.0$ week, $\mathrm{p}<0.001)$. Furthermore, surgical resection was one of the most powerful prognostic factor for favorable survival in the multivariate analysis. (HR 0.23, 95\% CI 0.08-0.66, p=0.006).

The treatment for intracranial metastasis from HCC may be similar to the general guidelines on metastatic brain tumors. In a single large lesion $(>3 \mathrm{~cm})$, especially with a significant mass effect ( $>1 \mathrm{~cm}$ midline shift), surgical resection should be considered with/without following whole brain radiotherapy (WBRT). Although the role of surgical resection for multiple brain metastases has not been established, surgery could be tried in cases with large lesions or significant mass effects and in cases where two or more lesions are accessible through a single craniotomy approach [14]. In the present study, it is difficult to conclude how the surgical resection could extend the patient's survival. Surgical resection decreased the possibility of the death from neurologic origins (13\% in surgical resection group $v s$ $40 \%$ in radiation treatment group and $83 \%$ in palliative treatment group). This finding might be explained by the clinical course of hemorrhagic HCC metastasis. Han et al. [7] found that recurrent intracranial bleeding after treatment was frequently found in the patients who had presented with overt intratumoral hemorrhage. However, the patients who did better after surgical resection were likely the group of patients who had intracranial lesions in a less eloquent area or better overall prognostic factors or health status. This would confound the results in a view of treatment effect versus patient selection effect.

Child-Pugh classification was also an important prognostic factor in our analysis. Child-Pugh classification is the most commonly used criterion to evaluate the status of liver function. The rate of complications, hemorrhage and mortality increase with poor liver function, especially in patients with HCC or liver cirrhosis [15]. Choi et al. [6] reported that the Child-Pugh classification was shown to influence the median survival time in patients with brain metastasis from HCC. In our study, Child-Pugh classification A group had a longer median survival time than Child-Pugh classification B/C group (14.4 weeks $v s$ 4.7 weeks, $\mathrm{p}=0.038)$. On multivariate analysis, good liver 

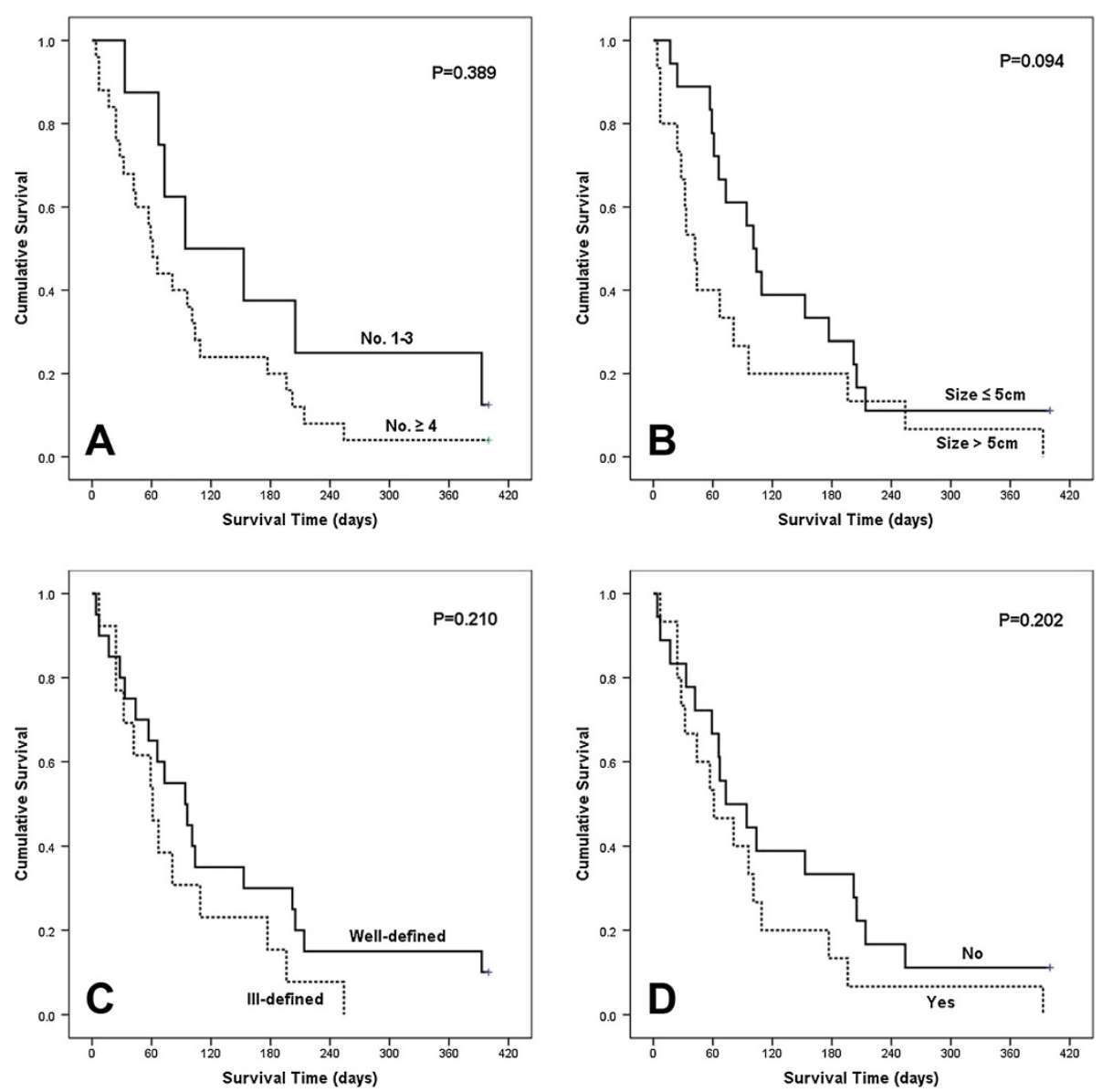

Figure 3 Kaplan-Meier analyses of overall survival for 33 patients according to HCC characteristics. (overall comparison was estimated using a log-rank test). A: Number of nodule, B: Size of the largest nodule, C: Type of HCC, D: Presence of portal vein thrombosis.

function at the time of brain metastasis was one of the most powerful prognostic factor for favorable survival (HR 0.06, 95\% CI 0.01-0.37, $\mathrm{p}=0.002$ ).

The median interval from initial HCC diagnosis to brain metastasis was 18.3 months in our study. It was similar to that in the previous studies, with the median interval ranging from 10.5 to 18.5 months. Some investigators, despite statistical insignificance, reported that the patients with a longer interval ( $\geq 12$ months) from initial HCC diagnosis to brain metastasis had a relatively longer survival than patients with a shorter interval ( $<12$ months) from initial HCC diagnosis to brain metastasis $[6,13]$. In our study, however, the patients with a shorter interval ( $<12$ months) from diagnosis of primary tumor to brain metastasis showed longer survival than the patients with a longer interval ( $\geq 12$ months) from diagnosis of primary tumor to brain metastasis without statistical significance in multivariate analysis (15.6 weeks vs 8.7 weeks, $\mathrm{p}=0.089$ ). Presumably, this result may be due to the declining general conditions of HCC patients. In other words, patients with a longer interval from diagnosis of primary tumor to brain metastasis might have worse general conditions following prolonged clinical progression than patients with a shorter interval from diagnosis of primary tumor to brain metastasis.

Previous studies have reported that brain metastasis from $\mathrm{HCC}$ is frequently associated with intratumoral hemorrhage $[5-7,12,13]$. This can be explained by the hypervascularity of $\mathrm{HCC}$ or a possible coagulopathy due to liver cirrhosis [6]. There is a controversy over the effect of intratumoral hemorrhage of brain metastasis on survival in HCC patients. Jiang et al. [13] reported that the patients without intratumoral hemorrhage had a longer survival time than patients with intratumoral hemorrhage, although statistical significance was not reached. Hsieh et al. [12], on the contrary, reported that the presence of intratumoral hemorrhage did not influence the overall survival in patients with brain metastasis from HCC. In our study, 51.5\% of patients presented with intratumoral hemorrhage, and patients without intratumoral hemorrhage had a longer survival time than patients with intratumoral hemorrhage (13.7 weeks vs 8.1 weeks, $\mathrm{p}=0.044$ in univariate analysis). 
Table 3 Previously published case-series in the literature of brain metastasis from HCC

\begin{tabular}{|c|c|c|c|c|c|c|c|}
\hline Author (year) & $\begin{array}{l}\text { Patient } \\
\text { number }\end{array}$ & $\begin{array}{l}\text { Age } \\
\text { (median) }\end{array}$ & $\begin{array}{l}\text { Median interval between } \\
\text { diagnosis of HCC and } \\
\text { brain metastasis (months) }\end{array}$ & $\begin{array}{l}\text { Median } \\
\text { survival } \\
\text { (weeks) }\end{array}$ & $\begin{array}{l}\text { Treatment for } \\
\text { brain metastasis }\end{array}$ & $\begin{array}{l}\text { Survival } \\
\text { time } \\
\text { (weeks) }\end{array}$ & Positive prognostic factor \\
\hline \multirow[t]{2}{*}{ Chang et al. (2004) } & \multirow[t]{2}{*}{45} & \multirow[t]{2}{*}{ NA } & \multirow[t]{2}{*}{10.5} & \multirow[t]{2}{*}{4} & $\begin{array}{l}\text { Resection and/or } \\
\text { radiotherapy }\end{array}$ & $>16$ & \multirow[t]{2}{*}{ Single lesion } \\
\hline & & & & & Supportive care & $<4$ & \\
\hline \multirow[t]{3}{*}{ Choi et al. (2009) } & \multirow[t]{3}{*}{62} & \multirow[t]{3}{*}{54} & \multirow[t]{3}{*}{18.2} & \multirow[t]{3}{*}{6.8} & Resection and WBRT & 33.6 & \multirow{3}{*}{$\begin{array}{l}\text { Single lesion, Child-Pugh's } \\
\text { classification A Any treatment } \\
\text { modalities for brain metastasi }\end{array}$} \\
\hline & & & & & $\begin{array}{l}\text { Resection or WBRT } \\
\text { or GKS }\end{array}$ & 10 & \\
\hline & & & & & Steroids alone & 2 & \\
\hline Hsieh et al. (2009) & 42 & 55.8 & 15.4 & 4.8 & NA & NA & $\mathrm{ICH}$ did not influence \\
\hline \multirow[t]{2}{*}{ Han et al. (2010) } & \multirow[t]{2}{*}{20} & \multirow[t]{2}{*}{55} & \multirow[t]{2}{*}{18.5} & \multirow[t]{2}{*}{8} & Resection and WBRT & 8 & \multirow{2}{*}{$\begin{array}{l}\text { Younger age, Extracranial } \\
\text { metastasis }\end{array}$} \\
\hline & & & & & WBRT and/or GKS & 16 & \\
\hline \multirow[t]{2}{*}{ Jiang et al. (2012) } & \multirow[t]{2}{*}{41} & \multirow[t]{2}{*}{48.5} & \multirow[t]{2}{*}{15} & \multirow[t]{2}{*}{12} & $\begin{array}{l}\text { Resection or WBRT } \\
\text { or GKS }\end{array}$ & 18 & \multirow{2}{*}{$\begin{array}{l}\text { No extracranial metastasis, } \\
\text { Low RPA class, Any treatment } \\
\text { modalities for brain metastasi }\end{array}$} \\
\hline & & & & & Steroids alone & 10.8 & \\
\hline \multirow[t]{3}{*}{ Present Study (2013) } & \multirow[t]{3}{*}{33} & \multirow[t]{3}{*}{62} & \multirow[t]{3}{*}{18.3} & \multirow[t]{3}{*}{10.4} & $\begin{array}{l}\text { Resection/ } \\
\text { Resection+WBRT }\end{array}$ & 25.3 & \multirow{3}{*}{$\begin{array}{l}\text { No intratumoral bleeding } \\
\text { Child-Pugh's classification A, } \\
\text { Resection for brain metastasis }\end{array}$} \\
\hline & & & & & WBRT/GKS/WBRT+GKS & 10.4 & \\
\hline & & & & & Steroids alone & 1.0 & \\
\hline
\end{tabular}

Additionally, the presence of intratumoral hemorrhage was the one of the prognostic factors for patient survival (HR 0.19, 95\% CI 0.07-0.55, p=0.002). As previously noted, hemorrhagic events frequently recurred in the cases with intratumoral hemorrhage, always drawn into the dismal prognosis. In addition, sudden neurological deterioration as in cerebrovascular accidents can lead to severe neurological deficits and poor functional status, which made the patients hesitating in selection for further adjuvant treatments, especially in the patients with underlying coagulopathy due to poor liver function state.

The RPA class has been suggested as an independent prognostic factor for the patients with brain metastasis from HCC. This result implies that patients with RPA class I and II may benefit from aggressive treatment [13]. Some studies revealed that the patient with low RPA class demonstrated longer survival than those with high RPA class [6,7]. Although patients with low RPA class (I and II) survived longer than patients with RPA class III in univariate analysis (13.4 weeks vs 2.4 weeks, $\mathrm{p}=0.001$ ) in our study, RPA class was not an independent prognostic factor in multivariate analysis $(\mathrm{p}=0.575)$. The number of metastatic brain lesions can be an important prognostic factor. It was reported that the patients with single lesions had a longer survival time than the patients with multiple lesions [6]. Similarly, in our study, the median survival of patients with a single lesion was longer than that of patients with multiple lesions, although statistical significance was not reached (13.7 weeks vs. 8.1 weeks, $\mathrm{p}=0.341$ ). Han et al. [7] reported that younger patients less than 60 years of age can be considered as a positive prognostic factor. Our study also showed that younger patients survived longer than older patients with a marginal statistical significance (14.8 weeks vs 8.7 weeks, $\mathrm{p}=0.096)$. However, younger age was not an independent favorable prognostic factor in the multivariate analysis $(p=0.062)$. Although good performance status (ECOG performance status grade $0-2$ ) has been reported as a positive prognostic factor [6], it did not show statistical significance as a prognostic factor in our study. HCC characteristics including the number of nodule, size of the largest nodule, type and presence of portal vein thrombosis were not correlated with the survival time of the patients. Furthermore, these were not independent prognostic factors in multivariate analysis, despite marginal statistical significances in some factors (presence of portal vein thrombosis [ $\mathrm{p}=0.065]$, HCC type [p $=0.065]$, number of nodule $[\mathrm{p}=0.088])$.

\section{Conclusion}

Although there have been some studies for identifying the prognostic factors for HCC patients with brain metastasis, it is challenging to specify the appropriate therapeutic strategy considering its rare incidence and poor prognosis. This study was basically a retrospective investigation of a relatively small number of patients. Therefore, there may be a possibility of selection bias and missed cases. And there was no information of the quality of life in the patients after various treatment modalities. To determine an appropriate therapeutic strategy for patients 
with brain metastasis from $\mathrm{HCC}$, a further prospective randomized study based on the survival and quality of life is needed.

In addition to the treatment modality for brain metastasis and liver function at the diagnosis of brain metastasis, presence of intratumoral hemorrhage was an independent prognostic factors for survival. Although HCC patients with brain metastasis showed a very poor prognosis with a 1-year survival rate of $6 \%$, surgical intervention was shown to lead to relative prolongation of the survival time, especially in those with preserved hepatic function.

\section{Abbreviations}

CT: Computed tomography; GKS: Gamma knife radiosurgery;

HCC: Hepatocellular carcinoma; MRI: Magnetic resonance imaging;

WBRT: Whole brain radiotherapy.

\section{Competing interest}

The authors declare that they have no competing interests.

\section{Authors' contributions}

MSH \& KSM analyzed the data and drafted manuscript. KHL \& SBC revised manuscript critically for important intellectually content. KHL \& WYJ performed the statistical analysis. SHL \& WYJ helped acquisition and interpretation of data. TYJ \& IYK participated in reviewing literatures and helped in conception and design of the study. KSM \& SJ conceived the study, participated in the design of it and coordination. All authors read and approved the final manuscript.

\section{Author details}

'Department of Neurosurgery, Chonnam National University Research Institute of Medical Sciences, Chonnam National University Hwasun Hospital \& Medical School, Gwangju, South Korea. ${ }^{2}$ Department of Pathology, Chonnam National University Research Institute of Medical Sciences, Chonnam National University Hwasun Hospital \& Medical School, Gwangju, South Korea. ${ }^{3}$ Department of Internal Medicine, Chonnam National University Research Institute of Medical Sciences, Chonnam National University Hwasun Hospital \& Medical School, Gwangju, South Korea.

Received: 6 June 2013 Accepted: 27 November 2013

Published: 1 December 2013

\section{References}

1. El-Serag HB: Hepatocellular carcinoma: an epidemiologic view. J Clin Gastroenterol 2002, 35:S72-S78.

2. Kim M, Na DL, Park SH, Jeon BS, Roh JK: Nervous system involvement by metastatic hepatocellular carcinoma. J Neurooncol 1998, 36:85-90.

3. Rahbari NN, Mehrabi A, Mollberg NM, Muller SA, Koch M, Buchler MW, Weitz J: Hepatocellular carcinoma: current management and perspectives for the future. Ann Surg 2011, 253:453-469.

4. Seinfeld J, Wagner AS, Kleinschmidt-DeMasters BK: Brain metastases from hepatocellular carcinoma in US patients. J Neurooncol 2006, 76:93-98.

5. Chang $L$, Chen YL, Kao MC: Intracranial metastasis of hepatocellular carcinoma: review of 45 cases. Surg Neurol 2004, 62:172-177.

6. Choi HJ, Cho BC, Sohn JH, Shin SJ, Kim SH, Kim JH, Yoo NC: Brain metastases from hepatocellular carcinoma: prognostic factors and outcome: brain metastasis from HCC. J Neurooncol 2009, 91:307-313.

7. Han JH, Kim DG, Park JC, Chung HT, Paek SH, Chung YS: Little response of cerebral metastasis from hepatocellular carcinoma to any treatments. J Korean Neurosci 2010, 47:325-331.

8. Oken MM, Creech RH, Tormey DC, Horton J, Davis TE, McFadden ET, Carbone PP: Toxicity and response criteria of the Eastern Cooperative Oncology Group. Am J Clin Oncol 1982, 5:649-655.

9. Lucey MR, Brown KA, Everson GT, Fung JJ, Gish R, Keeffe EB, Kneteman NM, Lake JR, Martin P, McDiarmid SV, et al: Minimal criteria for placement of adults on the liver transplant waiting list: a report of a national conference organized by the American Society of transplant physicians and the American association for the study of liver diseases. Liver Transp/ Surg 1997, 3:628-637.

10. Gaspar L, Scott C, Rotman M, Asbell S, Phillips T, Wasserman T, McKenna WG, Byhardt R: Recursive partitioning analysis (RPA) of prognostic factors in three Radiation Therapy Oncology Group (RTOG) brain metastases trials. Int I Radiat Oncol Biol Phys 1997, 37:745-751.

11. Murakami K, Nawano S, Moriyama N, Sekiguchi R, Satake M, Fujimoto H, Ichikawa T: Intracranial metastases of hepatocellular carcinoma: $\mathrm{CT}$ and MRI. Neuroradiology 1996, 38(Suppl 1):S31-S35.

12. Hsieh MJ, Lu CH, Tsai NW, Lui CC, Chuang YC, Huang CR, Chen SF, Chang CC, Chang HW, Chang WN: Prediction, clinical characteristics and prognosis of intracerebral hemorrhage in hepatocellular carcinoma patients with intracerebral metastasis. I Clin Neurosci 2009, 16:394-398.

13. Jiang XB, Ke C, Zhang GH, Zhang XH, Sai K, Chen ZP, Mou YG: Brain metastases from hepatocellular carcinoma: clinical features and prognostic factors. BMC Cancer 2012, 12:49.

14. Kalkanis SN, Kondziolka D, Gaspar LE, Burri SH, Asher AL, Cobbs CS, Ammirati M, Robinson PD, Andrews DW, Loeffler JS, et al: The role of surgical resection in the management of newly diagnosed brain metastases: a systematic review and evidence-based clinical practice guideline. J Neurooncol 2010, 96:33-43.

15. Chen CC, Hsu PW, Lee ST, Chang CN, Wei KC, Wu CT, Hsu YH, Lin TK, Lee SC, Huang YC: Brain surgery in patients with liver cirrhosis. J Neurosurg 2012, 117(2):348-353.

doi:10.1186/1471-2407-13-567

Cite this article as: Han et al: Brain metastasis from hepatocellular carcinoma: the role of surgery as a prognostic factor. BMC Cancer 2013 13:567.

\section{Submit your next manuscript to BioMed Central and take full advantage of:}

- Convenient online submission

- Thorough peer review

- No space constraints or color figure charges

- Immediate publication on acceptance

- Inclusion in PubMed, CAS, Scopus and Google Scholar

- Research which is freely available for redistribution 